\title{
High Resolution Transthoracic Ultrasound in Evaluation of Pediatric Mediastinal Lymphadenopathy
}

\author{
Manisha Jana $^{1}$ - Disha Mittal ${ }^{1} \cdot$ Ashu Seith Bhalla ${ }^{1}$. Priyanka Naranje ${ }^{1} \cdot$ Devasenathipathy Kandasamy $^{1}$. \\ Arun K. Gupta ${ }^{1}$
}

Received: 10 June 2020 / Accepted: 28 August 2020 / Published online: 2 September 2020

(C) Dr. K C Chaudhuri Foundation 2020

To the Editor: Traditionally, ultrasound (US) has not been used in the chest; with the exception of pleural pathologies and large peripheral masses. There has been a recent surge of interest in mediastinal US for lymph nodes (LN) [1, 2], similar to lung US in critical care scenario.

We evaluated the technical adequacy and accuracy of mediastinal US in detection and characterization of lymphadenopathy; on 15 children (during the period from July 2017 to October 2017) referred for contrast enhanced computed tomography (CECT) chest with the clinical or radiographic suspicion of mediastinal adenopathy. US was performed on a high end scanner using high frequency linear or endocavitary transducers. On US and CECT, LNs were assessed for distribution, number, size, shape, hilum, calcification and necrosis; while matting and enhancement pattern were assessed only on CECT. LNs were divided into three diagnostic categories on imaging: Normal, tubercular and alternate diagnosis. Final diagnosis was based on either cytopathology/ histopathology of LNs where available $(8 / 15)$; or based on a combination of clinical and labortary parameters, or sampling from any other accessible site (7/15). Out of 15; 7 children had tuberculosis (TB), 5 lymphoma, 2 reactive lymphadenopathy and 1 sarcoidosis.

US could detect LNs of 1R, 1L, 2R, 2L, 3A, 4R, 4L, 5, 6, 7, 10R stations; and was not useful in other stations; due to lack of proper acoustic window. In these stations; 45 LNs were classified as abnormal on US, and 50 on CT. In differentiating tubercular LN from other causes; US showed a sensitivity of $57.1 \%$, and CT $100 \%$. Both the modalities had $100 \%$ specificity. Similar experience has been reported in previous literatures [3-5].

Ashu Seith Bhalla

ashubhalla1@yahoo.com
While we found US to be equally good as CT in detecting abnormal LNs in accessible stations; characterization of LNs in terms of necrosis, matting, perinodal fat streakiness and rim enhancement was better in CT than US. Although the superiority of CT in mediastinal lymphadenopathy cannot be denied; repeated CTs in a child on anti-tubercular treatment comes with a high radiation burden. Hence, in TB endemic regions like India, US can act as a low-cost, radiation free alternative first line imaging for follow-up; especially suitable for use in children.

\section{Compliance with Ethical Standards}

Conflict of Interest None.

\section{References}

1. Moseme T, Andronikou S. Through the eye of the suprasternal notch: point-of-care sonography for tuberculous mediastinal lymphadenopathy in children. Pediat Radiol. 2014;44:681-4.

2. Hirche TO, Wagner TO, Dietrich CF. Mediastinal ultrasound: technique and possible applications. Med Klin (Munich). 2002;97:472-9.

3. Pool KL, Heuvelings CC, Bélard S, et al. Technical aspects of mediastinal ultrasound for pediatric pulmonary tuberculosis. Pediatr Radiol. 2017;47:1839-48.

4. Bosch-Marcet J, Serres-Créixams X, Borrás-Pérez V, Coll-Sibina MT, Guitet-Juliá M, Coll-Rosell E. Value of sonography for follow-up of mediastinal lymphadenopathy in children with tuberculosis. J Clin Ultrasound. 2007;35:118-24.

5. Bosch-Marcet J, Serres-Créixams X, Zuasnabar-Cotro A, CodinaPuig X, Català-Puigbó M, Simon-Riazuelo JL. Comparison of ultrasound with plain radiography and $\mathrm{CT}$ for the detection of mediastinal lymphadenopathy in children with tuberculosis. Pediatr Radiol. 2004;34:895-900.

Publisher's Note Springer Nature remains neutral with regard to jurisdictional claims in published maps and institutional affiliations.

1 Department of Radiodiagnosis, All India Institute of Medical Sciences, New Delhi 110029, India 